\title{
Certificação ambiental de habitações: um instrumento para ações sustentáveis na construção civil
}

Environmental certification of housing: an instrument for sustainable actions in civil construction

Certificación ambiental de la vivienda: un instrumento para acciones sostenibles en la construcción civil

LIMA, Maria Cristina Alves de Graduada em Engenharia Civil, UNINASSAU, Brasil mcristina.2411@gmail.com

SILVA, Ana Karla Batista da Mestranda em Engenharia Civil, UPE, Brasil anakarlabatista@hotmail.com

SILVA JUNIOR, Marcos Antonio Barbosa da Professor e Doutorando em Engenharia Civil, UFPE, Brasil marcos15barbosa@hotmail.com 


\section{RESUMO}

A adoção de práticas sustentáveis, na construção civil, pode ser facilitada, com o auxílio das empresas certificadoras, que direcionam as ações dos empreendedores na fase de execução das construções. Os Empreendimentos sustentáveis são edificações construídas que estão embasadas nos conceitos e procedimentos reconhecidos pela presença da sustentabilidade, desde a sua concepção até a sua construção e operação. Um projeto para ser sustentável deve ser ecologicamente correto, economicamente viável, socialmente justo e culturalmente aceito. A adoção de práticas sustentáveis na construção civil é "um caminho sem volta", pois diferentes agentes - tais como governos, consumidores, associações - alertam, estimulam e pressionam o setor da construção a incorporar essas práticas em suas atividades, não só com o objetivo de preservar o meio, mas também de garantir os recursos para as futuras gerações. Nesse contexto, o presente trabalho apresenta o processo certificatório dos dois mais conhecidos selos verdes no Brasil: o LEED (Leadership in Energy and Environmental Design) e o AQUA (Alta Qualidade Ambiental). A partir da revisão bibliográfica, constatou-se que o acréscimo de investimento na fase inicial da construção tem sido a maior dificuldade pela procura do Selo Verde. Apesar disso, o Brasil figura na quarta posição do ranking mundial de certificações LEED.

PALAVRAS-CHAVE: Construção Civil. Práticas sustentáveis. Certificação.

\section{SUMMARY}

The adoption of sustainable practices in civil construction can be facilitated, with the help of certifying companies, which direct the actions of entrepreneurs in the construction execution phase. Sustainable Projects are built buildings that are based on concepts and procedures recognized by the presence of sustainability, from their conception to their construction and operation. A project to be sustainable must be ecologically sound, economically viable, socially fair and culturally accepted. The adoption of sustainable practices in construction is a "no way back", as different agents - such as governments, consumers, associations - warn, encourage and pressure the construction sector to incorporate these practices in their activities, not only with the objective of to preserve the environment but also to secure resources for future generations. In this context, this paper presents the certification process of the two best known green seals in Brazil: LEED (Leadership in Energy and Environmental Design) and AQUA (High Environmental Quality). From the literature review, it was found that the increased investment in the initial phase of construction has been the greatest difficulty in seeking the Green Seal. Nevertheless, Brazil ranks fourth in the worldwide ranking of LEED certifications.

KEYWORDS: Construction. Sustainable practices. Certification.

\section{RESUMEN}

La adopción de prácticas sostenibles en la construcción civil puede facilitarse, con la ayuda de empresas certificadoras, que dirigen las acciones de los empresarios en la fase de ejecución de la construcción. Los proyectos sostenibles son edificios construidos que se basan en conceptos y procedimientos reconocidos por la presencia de la sostenibilidad, desde su concepción hasta su construcción y operación. Un proyecto para ser sostenible debe ser ecológicamente sólido, económicamente viable, socialmente justo y culturalmente aceptado. La adopción de prácticas de construcción sostenibles es un "no hay vuelta atrás", ya que diferentes actores, como gobiernos, consumidores, asociaciones, advierten, estimulan y presionan al sector de la construcción para que incorpore estas prácticas en sus actividades, no solo con el propósito. para preservar el medio ambiente pero también para asegurar recursos para las generaciones futuras. En este contexto, este documento presenta el proceso de certificación de los dos sellos verdes más conocidos en Brasil: LEED (Liderazgo en Energía y Diseño Ambiental) y AQUA (Alta Calidad Ambiental). A partir de la revisión de la literatura, se descubrió que la mayor inversión en la fase inicial de construcción ha sido la mayor dificultad para buscar el Sello Verde. Sin embargo, Brasil ocupa el cuarto lugar en el ranking mundial de certificaciones LEED.

PALABRAS CLAVE: Construcción civil. Prácticas sostenibles. Certificación 


\section{INTRODUÇÃO}

A construção civil está entre os setores que mais causam impactos ao meio ambiente. Foi pensando nisso que as ações sustentáveis foram surgindo em diversas partes do mundo. Nas últimas décadas, com o conceito de sustentabilidade na construção civil, a otimização das etapas de um empreendimento começa a partir do projeto (planejamento), passando pelas fases de execução (implantação), uso e manutenção. Esse processo deve ser de forma holística, garantindo assim a harmonia entre os ambientes naturais e construídos (DEGANI; CARDOSO, 2002).

A construção sustentável promove intervenções sobre o meio sem que haja o esgotamento dos recursos naturais, pensando nas gerações futuras. Além de proporcionar a integração entre os aspectos sociais e econômicos. Dentre os desafios que as empresas podem enfrentar, estão a redução e reutilização dos resíduos gerados, a diminuição e o melhoramento do consumo de materiais e de energia e a prática de regulamentações (SILVA; SILVA JUNIOR; SANTOS, 2018).

Preocupadas em manter uma boa colocação no mercado, as empresas procuram produzir produtos que atendam aos padrões de certificação ambiental. Sistemas de desempenho das edificações foram criados a fim de aprimorar a gestão dos recursos. Órgãos e certificações de desempenho ambiental e social, como LEED (Leadership in Energy and Environmental Design), desenvolvida nos Estados Unidos, e AQUA (Alta Qualidade Ambiental), certificação brasileira, foram criados para incentivar as práticas sustentáveis no setor e educar os consumidores sobre impactos ambientais de produção, uso e descarte, trazendo qualidade de vida tanto para os trabalhadores quanto para os usuários.

Com o objetivo de propor condições dos empreendimentos se tornarem sustentáveis, seja na redução dos custos, no combate ao desperdício e/ou no aprimoramento dos processos, os selos verdes imprimem uma conscientização de todos os envolvidos no processo construtivo e ressaltam a importância em reduzir o impacto ambiental gerado pelo empreendimento. Sendo assim, com a certificação de uma obra, todos os envolvidos estarão comprometidos com o meio ambiente, ainda que o objetivo da certificação pelo empreendedor seja apenas a valorização do imóvel.

\section{OBJETIVO}

Apresentar os processos das certificações ambientais LEED e AQUA como instrumentos de promoção das ações sustentáveis em obras brasileiras, destacando as vantagens e desvantagens no uso dos citados selos verdes.

\section{REFERENCIAL TEÓRICO}

\section{Conceitos e generalidades}


A Certificação Ambiental é uma declaração formal que atesta quais produtos e serviços são menos agressivos ao meio ambiente. Surgiu pela necessidade de diferenciar os produtos com desempenho ambientalmente adequado, por meio de todo o processo de produção, transporte e comercialização. Em suma, objetiva orientar o empreendedor a adotar práticas sustentáveis em seus negócios, produtos e serviços.

Os Selos Verdes visam analisar todo o processo produtivo, desde a obtenção da matéria prima, descarte dos resíduos, até a qualidade do produto e o seu uso. Segundo a BIO3 (2019), a certificação ambiental foi criada por um comitê internacional com representantes de 95 países responsáveis por cerca de $95 \%$ da produção mundial da indústria. Isso aconteceu nos anos 80 depois de graves acidentes ecológicos.

Os programas de rotulagem surgiram em 1894, nos Estados Unidos, a partir da criação de uma empresa que averiguava a veracidade das informações contidas nos rótulos dos produtos (CORREA, 1998). A aceitação dos rótulos orgânicos foi rápida. Segundo Andrade, Tachiwawa e Carvalho (2002) as rotulagens ambientais foram criadas com base em análise de ciclo de vida e fiscalizados por instituições governamentais ou não-governamentais (VIDIGAL, 2012). Os benefícios podem ser ambientais, sociais e econômicos, conforme observados no Quadro1.

Quadro 1 - Benefícios da rotulagem ambiental.

\begin{tabular}{|l|l|}
\hline Ambientais: \\
\hline - & Redução de problemas e impactos ambientais; \\
- & Melhora do desempenho ambiental (além do requerido na Lei). \\
\hline Sociais: \\
\hline - Aumento da satisfação do consumidor e melhoria das condições de vida: saúde, \\
Ecolicidade espiritual, etc. \\
\hline - Aumicos: \\
- Reconhecimento da liderança do mercado; \\
- Aumento da capacidade de inovação do produto; \\
- Melhoria das exportações; \\
- Credibilidade nos mercados; \\
\hline
\end{tabular}

Fonte: Adaptado da UNIRIO (2019).

O objetivo do programa de rotulagem ambiental é procurar despertar no consumidor a consciência e o entendimento dos conceitos sobre proteção ambiental e produção sustentável. Também tenta influenciar na escolha do consumidor ou no comportamento do fabricante visando o menor impacto ambiental. 
As vantagens oferecidas pelos rótulos se estendem desde a incrementação das vendas e agregação de valor a imagem de um produto, até o aumento da consciência dos consumidores, proporcionando informação exata que protege o meio ambiente.

\section{A importância da Certificação Ambiental}

Como uma forma de se colocar e se estabelecer no mercado mundial da construção civil, empresas passam a adotar programas de gerenciamento ambiental forçadas pelas exigências das normas técnicas, restrições de mercado e pelas rotulações ambientais. Segundo Guéron (2003), para países em desenvolvimento, um selo verde tem bastante relevância e demonstra a qualidade dos seus produtos para o mercado externo (via "qualidade ambiental"), servindo de importante estratégia comercial de valoração desses produtos.

É de suma importância o Selo Verde para a mudança nos padrões de consumo, pois além de orientar os consumidores a comprar produtos que agridem menos a natureza, incentiva os empreendedores a mudarem seus modelos de produção, visando à concorrência do mercado imobiliário (CORREA, 1998).

Com a prática da NBR ISO 14.001 (que avalia o sistema de gestão ambiental da empresa), é possível descobrir desperdícios e processos ineficientes. Isso possibilita a construção mais eficiente e com uma menor quantidade de matéria prima, além de produzir menos resíduos (VIDIGAL, 2012).

\section{O processo de certificação}

O processo das certificações ambientais constitui-se de quatro etapas, a saber:

1. Estudo de Viabilidade Técnica: Este estudo levará em consideração a utilização de energia e água, a gestão dos resíduos, a destinação da verba no setor de compras, dentre outros fatores que serão analisados. Nesta etapa são definidas as estratégias a serem adotadas.

2. Plano de Ação: Consiste na incorporação das estratégias definidas na fase anterior. É estabelecido um cronograma de implementação destas estratégias, definido juntamente com os gestores e empreendedores.

3. Fase de Implementação: Forma sistêmica de verificação e medição de resultados, e realização de ajustes (caso precise) de forma que sejam alcançadas com sucesso ao final do período.

4. Certificação Ambiental do Empreendimento: Obtém-se com toda a documentação de todo o processo e com a assessoria adequada.

As etapas de uma construção devem ser integradas. É necessária uma comunicação constante entre projetistas, arquitetos, engenheiros e a construtora. Essa integração propicia um aperfeiçoamento continuo do processo produtivo, levando a diminuição dos custos e a eficiência da execução das etapas. 


\section{A informação como aliada para o crescimento de obras sustentáveis}

Informar os consumidores a respeito dos produtos que causam menos impacto ao meio ambiente é fundamental, porém é necessário que a informação chegue ao consumidor não apenas como uma propaganda publicitária (SODRÉ, 2018).

A imagem da empresa vinculada aos produtos por meio do marketing verde acaba influenciando compradores na escolha do seu imóvel. Isso pode ser encarado como uma vantagem competitiva. O marketing verde funciona como um excelente instrumento de informação pois apresenta uma visão holística dos processos responsáveis por identificar, antecipar e satisfazer as necessidades dos clientes e da sociedade, de forma lucrativa e sustentável.

Para que a certificação ambiental seja aderida por um maior número de empresas, é necessário instruir a sociedade sobre os critérios e benefícios. A instrução possibilita a formação de uma consciência ambientalista de toda a sociedade, possibilitando assim, o questionamento e o exercício do seu direito ao meio ambiente.

\section{Certificação LEED (Leadership in Energy and Environmental Design)}

O LEED foi desenvolvido pelo US GBC (U. S. Green Building Council), instituição que promove edificações sustentáveis e produtivas. Em 2007, foi criado no Brasil o GBC Brasil (Green Building Council Brasil), órgão não governamental vinculado ao US GBC. Presente em mais de 160 países, com a missão de mudar a indústria da construção civil e a cultura da sociedade em relação à sustentabilidade. Suas principais atividades abrangem: capacitação profissional, disseminação de informações, certificação LEED e relações governamentais segundo o site da US GBC (US GBC, 2018).

O sistema LEED analisa a eficiência energética, hídrica e a redução dos gases do efeito estufa. Baseia-se em um número de pontos dividido em quatro níveis: Certificado (Certified), Prata (Silver), Ouro (Gold) e Platina (Platinum). A Figura 1 mostra os níveis de classificação da certificação LEED.

Figura 1 - Pontuação e níveis da certificação LEED.

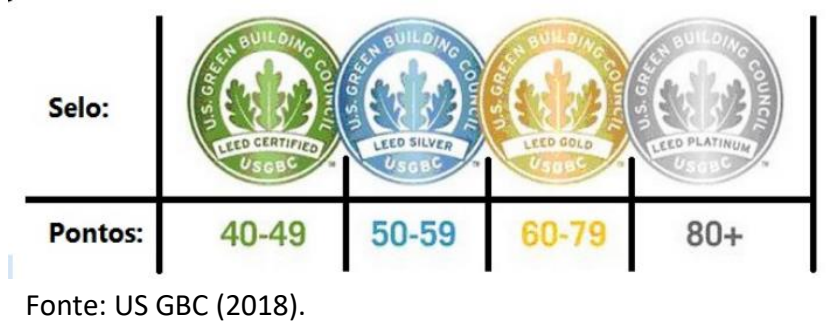

Esta certificação funciona para todos os edifícios e pode ser aplicada em qualquer fase do empreendimento. Dentro das 8 dimensões que deverão ser analisadas (Figura2), existem prérequisitos (práticas obrigatórias) e créditos (recomendações) que à medida que são atendidos, 
garantem pontos à edificação. A categoria da certificação é definida de acordo com a quantidade de pontos recebidos, podendo variar de 40 pontos a 110 pontos.

Depois de escolher a tipologia do projeto, as construtoras devem se registrar pelo LEED online e enviar os documentos exigidos. Então, é só aguardar a auditoria que irá avaliar a documentação e, caso esteja correto, receberá a certificação.

A certificação ambiental LEED objetiva promover a transformação do setor da construção civil por meio de estratégias desenvolvidas buscando alcançar: a mitigação da mudança climática global; melhorar a saúde da humanidade e o bem-estar do ocupante; a proteção e restauração de recursos hídricos; a proteção e restauração da biodiversidade e dos serviços ecossistêmicos. O aumento da comunicação e da educação que contribui para a equidade socioambiental e a qualidade de vida para todos de acordo com a UNIVEM (2019).

A abrangência da certificação LEED leva em consideração o ciclo de vida da construção em diferentes etapas e tipos como: residenciais, comerciais, públicos, edificações novas, edificações já existentes, manutenção e operação, conforme US GBC (2018).

Figura 2 - Quadro das dimensões avaliadas.

Dimensões Avaliadas

Sustainable sites (Espaço Sustentável) - Encoraja estratégias que minimizam o impacto no ecossistema durante a implantação da edificação e aborda questões fundamentais de grandes centros urbanos, como redução do uso do carro e das ilhas de calor.

Water efficiency (Eficiência do uso da água) - Promove inovações para o uso racional da água, com foco na redução do consumo de água potável e alternativas de tratamento e reuso dos recursos.

Energy \& atmosphere (Energia e Atmosfera) - Promove eficiência energética nas edificações por meio de estratégias simples $\mathrm{e}$ inovadoras, como por exemplo simulações energéticas, medições, comissionamento de sistemas e utilização de equipamentos e sistemas eficientes.

(A) Materials \& resources (Materiais e Recursos) - Encoraja o uso de materiais de baixo impacto ambiental (reciclados, regionais, recicláveis, de reuso, etc.) e reduz a geração de resíduos, além de promover o descarte consciente, desviando o volume de resíduos gerados dos aterros sanitários.

Indoor environmental quality (Qualidade ambiental interna) - Promove a qualidade ambiental interna do ar, essencial para ambientes com alta permanência de pessoas, com foco na escolha de materiais com baixa emissão de compostos orgânicos voláteis, controlabilidade de sistemas, conforto térmico e priorização de espaços com vista externa e luz natural.

(6) Innovation in design or innovation in operations (Inovação e Processos) - Incentiva a busca de conhecimento sobre Green Buildings, assim como, a criação de medidas projetuais não descritas nas categorias do LEED. Pontos de desempenho exemplar estão habilitados para esta categoria.

P Regional priority credits (Créditos de Prioridade Regional) - Incentiva os créditos definidos como prioridade regional para cada pais, de acordo com as diferenças ambientais, sociais e econômicas existentes em cada local.. Quatro pontos estão disponiveis para esta categoria.

Fonte: US GBC (2018).

Certificação AQUA (Alta Qualidade Ambiental) 
O selo AQUA é a primeira norma brasileira para certificação sustentáveis. Como o processo AQUA atende às necessidades legislativas, de clima e de fontes de energia do Brasil, é mais adaptado à nossa realidade do que selos como o LEED (muito utilizado mundialmente). Foi criado em 2008, através da Fundação Vanzolini (instituição sem fins lucrativos) pelos professores do Departamento de Engenharia de Produção da Escola Politécnica da Universidade de São Paulo (USP) segundo Vanzolini (2019).

O processo de certificação é montado em torno dos aspectos relacionados ao sistema de gestão ambiental (empreendedor), a adaptação do ambiente e informações transmitidas pelo empreendedor aos usuários. Desta forma, o referencial técnico de certificação se estrutura em dois elementos:

$\checkmark$ SGE (Sistema de Gestão do Empreendimento): avalia o sistema de gestão ambiental implementado; $\mathrm{e}$

$\checkmark$ QAE (Qualidade Ambiental do Edifício): avalia o desempenho arquitetônico e técnico do edifício.

Para a obtenção do selo, é necessário passar por quatro fases: Programa, Concepção (Projeto), Realização (Obra) e Operação (Uso). Nestas fases, são avaliados quatorze critérios distribuídas em quatro famílias, conforme mostrado no Quadro 2.

Quadro 2 - Critérios avaliativos do processo AQUA.

\section{Sítio e Construção:}

1- Relação do edifício com o seu entorno

2- Escolha integrada de produtos, sistemas e processos construtivos

3- Canteiros de obras com baixo impacto ambiental

\section{Gestão:}

4- Gestão da água

5- Gestão da energia

6- Gestão dos resíduos de uso e operação do edifício

7- Manutenção: permanência do desempenho ambiental

\section{Conforto:}

8- Conforto higrotérmico

9- Conforto acústico

10- Conforto visual

11- Conforto olfativo

\section{Saúde:}

12- Qualidade sanitária dos ambientes

13- Qualidade sanitária do ar

14- Qualidade sanitária da água 
Fonte: Adaptado de VANZOLINI (2019).

Diferentemente do LEED, que considera pontos para avaliar cada critério, o processo AQUA realiza uma avaliação a partir dos 14 critérios e emite uma classificação:

- Bom: é o mínimo aceitável para um empreendimento de Alta Qualidade Ambiental.

- Superior: possui boas práticas de sustentabilidade.

- Excelente: corresponde aos desempenhos máximos constatados em empreendimentos de Alta Qualidade Ambiental.

Este perfil de Qualidade Ambiental do Edifício (QAE) é próprio a cada situação. É necessário que o desempenho nos 14 critérios do processo AQUA seja "excelente" em, pelo menos, 3 categorias, "superior" em 4 e "bom" em 7, segundo Vanzolini (2019).

Uma das grandes vantagens da Certificação AQUA para o Brasil, segundo Vanzolini (2019), é o de que ele contém critérios adaptados ao país que exigem resultados de desempenho, não prescrevendo soluções de projeto pré-concebidas.

\section{METODOLOGIA}

Para a abordagem, realizou-se uma pesquisa bibliográfica identificando os estudos com temas relativos à certificação ambiental, focando nas certificações LEED e AQUA. Por meio da análise documental, foi possível conhecer a realidade da certificação ambiental no Brasil, além de identificar as principais dificuldades enfrentadas pelos empreendedores para a obtenção dos selos verdes.

Por se tratar de artigo de revisão de literatura, os dados secundários utilizados foram coletados de produções científicas em forma de livros, artigos, dissertações, teses e materiais publicados na internet em sites especializados.

\section{RESULTADOS}

Como resultados, serão apresentados, a seguir, os benefícios e as dificuldades da certificação ambiental, apresentando um panorama da realidade brasileira quanto à questão dos selos verdes.

\section{Benefícios}

Em linhas gerais, os benefícios do processo de certificação ambiental dos empreendimentos são os seguintes:

- Reconhecimento da comunidade nacional e internacional com a imagem do empreendimento associada à preservação ambiental;

- A identificação das atividades poluidoras e o desperdício de materiais e energia;

- A otimização do tempo de produção que refletem na economia de energia; 
- A imagem da empresa que fica associada à alta qualidade ambiental e ainda melhora o relacionamento dos órgãos ambientais e a comunidade;

- Quanto aos usuários estes imóveis apresentam uma economia direta no consumo de água e de energia elétrica;

- Apresentam melhores condições de conforto e saúde;

- As obras apresentam um menor impacto à vizinhança, sem falar no melhor aproveitamento da infraestrutura local;

- Segundo MacNaughton et al. (2018), os prédios com selos verdes ao longo de um período de 16 anos nos Estados Unidos, China, Índia, Brasil, Alemanha e Turquia, descobriu que os edifícios mais sustentáveis geraram 6 bilhões de dólares em benefícios combinados para saúde e clima, graças à redução de emissões de gases poluentes;

- Menos 33 mil toneladas de $\mathrm{CO}_{2}$ não emitidos a natureza, isso equivale à remoção de 7,1 milhões de carros de passageiros por um ano nas estradas (MACNAUGHTON et al., 2018).

- Economia de 7,5 bilhões de dólares em consumo de energia conforme pesquisadores de Harvard que descobriram, a média, para cada dólar economizado em custos de energia para construções verdes, outros 77 centavos foram economizados em benefícios para a saúde e o clima; e na China e na Índia os efeitos foram ainda maiores, cerca de US 10,00 em benefícios para a saúde e clima para cada dólar economizado em energia, ainda segundo MacNaughton et al. (2018).

\section{Dificuldades}

No Brasil, existe a cultura de priorização dos custos de implementação e de menor valorização dos custos de uso, manutenção, demolição e destinação (JOHN; OLIVEIRA; LIMA, 2007). Isso pode ser um fator que dificulta a opção pela construção de edificações sustentáveis, que demanda maior custo inicial, através de esforços para atender os requisitos de uma certificação e com o custo da própria certificação. A seguir, foram reunidos e listados os principais problemas para a implementação de edifícios sustentáveis:

- Obtenção da certificação necessária junto a fornecedores, projetistas, construtora e consultores;

- Documentação necessária e burocracia excessiva;

- Falta de experiência dos integrantes da equipe de projetos;

- Falta de cooperação entre os agentes envolvidos no projeto;

- A falta de treinamento e educação em projetos e construções sustentáveis;

- Maior complexidade na construção;

- Maior custo inicial;

- Desinteresse por parte do mercado;

- Ausência de critério específico para inovação

- A ideia de que práticas sustentáveis geram um aumento nos custos e redução nos lucros das empresas;

- Falta de mão de obra qualificada; 
- Rotatividade de funcionários;

- Investimento inicial mais elevado do que as construções convencionais;

- A falta de embasamento científico para os critérios atendidos para a certificação LEED;

- O sistema LEED está incorporado somente à porção mais elevada do mercado, contribuindo pouco para diminuir a desigualdade desse mercado no Brasil.

O uso irrestrito da certificação LEED pode induzir ao fenômeno greenwash ("maquiagem" para tentar passar a ideia de que são ecoeficientes), por focar em critérios como a utilização de novas tecnologias e produtos certificados e não se fundamentar na qualidade do projeto em seu contexto local, induzindo apenas ao consumo e ao mercado.

Em síntese, os pontos negativos estão associados mais em seu conceito de avaliação e sua abrangência. Além do mais, uns dos aspectos mais negativos estão relacionados, segundo Hernandes (2006) a falta de normas brasileiras para auxiliar na aplicação desse sistema.

\section{Investimento}

Existem dois custos, o de implantação e o custo de processo. $O$ custo de implantação consiste na contratação de uma consultoria que irá implementar o sistema de gestão ambiental, passando pelo treinamento dos funcionários e a criação de um sistema de monitoramento que irá garantir a eficiência do sistema. Já o custo de processo consiste nos investimentos de melhoria ou substituição de processos. Este último é mais difícil de estimar.

Segundo Casado (2011) o investimento inicial de uma construção verde é maior do que uma construção convencional, porém os custos operacionais dessa edificação serão menores durante toda a sua vida útil, propiciando o retorno desse acréscimo do investimento inicial entre três e cinco anos.

\section{Profissionais Certificados}

Cerca de 250 profissionais brasileiros, ou seja, $0,26 \%$ do total de 95.000 arquitetos do país detêm a certificação LEED. Nos Estados Unidos são 175.000 profissionais qualificados (GBC BRASIL, 2019). Os arquitetos brasileiros pouco se interessam em obter esta certificação LEED pelo fato de ser onerosa. Já para os profissionais que trabalham para grandes corporações se torna indispensável.

Para receber esta certificação, engenheiros e arquitetos devem passar por um curso com duração de dois dias, ministrado pelo GBC Brasil, depois terão que fazer uma prova contendo 200 questões para serem respondidas em um intervalo de quatro horas. $O$ valor varia de 200 a 550 dólares, conforme a certificação desejada (GBC BRASIL, 2019). 


\section{Realidade brasileira da certificação ambiental na construção civil}

Segundo os dados até dezembro de 2018 (GBC BRASIL, 2019), há no Brasil 1.345 projetos registrados e destes, 533 certificados. $O$ ano de 2018 foi o 50 melhor período de certificações LEED no Brasil, considerando os 11 anos de atuação do GBC no país (desde 2007). Os edifícios comerciais de alto padrão continuam liderando os certificados, tanto em número de registros quanto em certificações. Apesar disso, tem-se observado que os edifícios verdes estão chegando às escolas, creches, hospitais, entre outras edificações, públicas ou privadas.

O Brasil é um dos pioneiros a implementar uma certificação voltada a aceleração da geração de energia por fontes renováveis - Certificação Zero Energy Building. Em termos de Certificações Verdes, a taxa anual de crescimento de edifícios sustentáveis no Brasil é de $41 \%$, já na região sul esse aumento é de 79,6\% (GBC BRASIL, 2019).

Tendo como referência a certificação LEED, o Brasil se encontra na 4a posição no Ranking Mundial de 2018 (US GBC, 2018), atrás dos EUA com 68.600 registros e 33.316 certificações, da China com 3.743 registros e 1.518 certificados, e da Índia com 1.776 projetos registrados e 691 certificados. O Ranking Anual dos 10 países e regiões com maior número de projetos LEED, considerando informações até 31 de dezembro de 2018, compõe 4.952 projetos certificados (US GBC, 2018; GBC BRASIL, 2019). A lista não inclui os EUA, país de origem do LEED, que se mantém como maior mercado mundial.

Em 2014, o Brasil conseguiu a 2ạ posição no ranking de edificações esportivas com certificação LEED no mundo (GBC BRASIL, 2019).

São Paulo é o estado brasileiro com mais registros e certificações LEED, com 719 e 301 respectivamente. Completando as cinco primeiras posições estão Rio de Janeiro, Paraná, Minas Gerais e Rio Grande do Sul. Na Região Nordeste, Pernambuco é estado com mais registros e certificações LEED, estando em 7o no ranking Brasil em 2018 (GBC BRASIL, 2019).

\section{Viabilidade financeira}

Selo Verde varia entre $3 \%$ e $6 \%$ do custo total da obra. O custo operacional de um prédio sustentável fica entre $8 \%$ e $9 \%$ mais barato durante a sua fase de operação (GBC BRASIL, 2019). Os edifícios verdes são viáveis, tanto para os construtores quanto para os que habitam, pois, a alta qualidade desses empreendimentos além de influenciar no bolso, também influencia no bem-estar das pessoas.

Além dos benefícios sociais e ambientais, a construção sustentável se apresenta como um excelente negócio no setor imobiliário, agregando valor ao imóvel e propiciando um menor custo operacional das edificações.

O estudo de Costa et al. (2018) aponta que apenas o fator "certificação LEED", independente de outros fatores como localização, tamanho, dentre outros, favorece uma valorização por metro quadrado no aluguel de $4 \%$ a $8 \%$. Isto sem prejudicar a ocupação, pelo contrário, a taxa de 
vacância dos edifícios verdes é de $28,6 \%$ contra $34,1 \%$ das edificações tradicionais. 0 estudo analisou mais de 2.000 prédios comerciais na cidade de São Paulo entre o 10 trimestre de 2010 e o $3^{\circ}$ trimestre de 2014. Prédios verdes possuem taxas de condomínio menores, em torno de $20 \%$.

\section{CONCLUSÃO}

O setor da construção civil no Brasil é marcado por grandes divergências. De um lado são as necessidades básicas que precisam ser atendidas, como a parte da infraestrutura das áreas carentes; por outro lado, as grandes construtoras precisam atender as necessidades do mercado mundial. Sendo assim, as empresas recorrem às certificações ambientais como um diferencial para se manter no mercado. A certificação LEED é a mais adotada e aceita no país.

O Brasil se encontra (até o final de 2018) como o 40 país no ranking mundial da certificação LEED, atrás dos EUA, China e Índia (US GBC, 2018). Ainda segundo os dados do GBC Brasil (2019), existe no Brasil 1.345 projetos registrados e destes, 533 já são certificados. Isso é um ponto muito positivo do ponto de vista de ser uma nação em desenvolvimento e que vem passando por uma fase de recessão no setor de habitação. Em 2014, o Brasil conseguiu a 2a posição no ranking mundial de edificações esportivas do selo LEED, ficando atrás apenas dos EUA.

Quanto às dificuldades para obtenção do selo verde, se destacam a ideia de que práticas sustentáveis geram um aumento nos custos e redução nos lucros das empresas. Embora ainda haja grande resistência em relação ao custo inicial para a adoção dos selos verdes, os grandes empreendimentos não abrem mão deste artifício, pois sabem que uma obra certificada propicia vantagens na hora da concorrência. A certificação ambiental muitas vezes é encarada como uma forma de valorização do imóvel.

Quanto à questão da viabilidade da construção sustentável, para os construtores, o principal motivo pelo o qual eles apostam na certificação é que a venda desses imóveis é mais rápida do que as construções tradicionais. Já os clientes, visam principalmente o menor custo de operação. Mas o principal de tudo é que tais construções trazem benefícios ambientais e sociais, bem como uma melhor qualidade de vida para os seus usuários. Sem falar que a construção sustentável se apresenta como um ótimo negócio do setor imobiliário. E vale ressaltar que além da valorização do imóvel, a taxa de vacância dos edifícios verdes é de $28,6 \%$ contra $34,1 \%$ das edificações tradicionais.

No contexto mais local, a cidade do Recife e Região Metropolitana apresenta um panorama com grandes empreendimentos certificados, como a Arena Pernambuco (LEED), o Sheraton Reserva do Paiva Hotel \& Convention Center (LEED), o Shopping Camará (LEED), o Shopping Rio Mar (AQUA), entre outros. Não podendo esquecer o "Selo Verde Recife" que vem agregar essa conscientização ambiental, apresentando exigências mais direcionadas à realidade local. 
Estudos futuros deverão ser realizados com o objetivo de complementar essa pesquisa com a verificação do panorama de cada região do Brasil, mostrando as suas principais dificuldades e comparando-as para ver quais as principais diferenças entre elas.

\section{REFERÊNCIAS BIBLIOGRÁFICAS}

ANDRADE, R. O. B.; TACHIWAWA, T.; CARVALHO, A. B. Gestão Ambiental - Enfoque estratégico aplicado ao desenvolvimento sustentável. São Paulo: Pearson Education do Brasil, 2002.

ASSOCIAÇÃO BRASILEIRA DE NORMA STÉCNICAS. NBR ISO 14.001: Sistemas de gestão ambiental - Requisitos com orientações para uso. Rio de Janeiro, 2015.

BIO3. Certificação ambiental: porque se adequar e quais os seus benefícios. Disponível em: https://www.bio3consultoria.com.br/certificacao-ambiental/. Acesso em: 12 out. 2019

CASADO, M. Green buildings, antes tarde do que nunca. Revista CREA-ES, edição Junho, 2011.

CORREA, L. B. C. G. Comércio e meio ambiente: atuação diplomática brasileira em relação ao selo verde. Brasília: Instituto Rio Branco, Fundação Alexandre de Gusmão, Centro de Estudos Estratégicos, 1998.

COSTA, O.; FUERST, F.; ROBINSON, S. J.; MENDES-DA-SILVA, W. Green label signals in an emerging real estate market. A case study of Sao Paulo, Brazil. Journal of Cleaner Production, v. 184, p. 660-670, 2018.

DEGANI, C. M.; CARDOSO, F. F. A sustentabilidade ao longo do ciclo de vida de edifícios: a importância da etapa de projeto arquitetônico. In: NUTAU 2002 - Sustentabilidade, Arquitetura e Desenho Urbano. Núcleo de Pesquisa em Tecnologia da Arquitetura e Urbanismo da Faculdade de Arquitetura e Urbanismo da Universidade de São Paulo. São Paulo, 7 a 11 de outubro, 2002.

FUNDAÇÃO GETÚLIO VARGAS. Essays in Commercial Real Estate Investments. Disponível em: http://bibliotecadigital. fgv.br/ojs. Acesso em: 28 out. 2019.

GBC BRASIL. Anuário GBC Brasil 2019. Disponível em: https://www.gbcbrasil.org.br/anuario-gbc-brasil-2019/. Acesso em: 28 out. 2019.

GUERÓN, A. L. Rotulagem e certificação ambiental: uma base para subsidiar a análise da certificação florestal no Brasil. UFRJ, Rio de Janeiro, 2003.

HERNANDES, T. Z. LEED-NC como sistema de avaliação da sustentabilidade: uma perspectiva nacional? Tese (Mestrado na Área de Concentração: Tecnologia da Arquitetura) - FAUUSP, São Paulo, 2006.

JOHN, V. M.; OLIVEIRA, D. P.; LIMA, J. A. R. Levantamento do estado da arte: Seleção de materiais. Projeto Tecnologias para construção habitacional mais sustentável, Documento 2.4, São Paulo-SP, 2007.

MACNAUGHTON, P.; CAO, X; BUONOCORE, J.; CEDENO-LAURENT, J.; SPENGLER, J.; BERNSTEIN, A.; ALLEN, J. Energy Savings, Emission Reductions, and health Co-benefits of the green Building Movement. Journal of Exposure Science \& Environmental Epidemiology, vol. 28, pp. 307-318, 2018.

SILVA, A. K. B.; SILVA JUNIOR, M. A. B.; SANTOS, C. P. Sustentabilidade na construção civil: Um panorama dos dispositivos legais vigentes e das práticas adotadas na cidade do Recife-PE. In: XIV Fórum Ambiental Alta Paulista, São Paulo, 11 p, 2018.

SODRÉ, M. G. Consumidor e a Rotulagem Ambiental. Disponível em: https://sustentarqui. com.br/brasil-e-o-4o-paisno-mundo-em-numeros-de-certificacoes-leed/. Acesso em: 13 nov. 2018.

UNIRIO. Núcleo de Gestão Ambiental. Disponível em: https://sites.google.com/site/ngaunirio/cap-6-certificao-erotulagem-ambiental. Acesso em: 28 nov. 2019. 
UNIVEM. A Educação Sustentável do Consumidor e os Efeitos do Consumo Exacerbado no Mundo Capitalista. Disponível em: http://www2.univem.edu.br. Acesso em: 28 out. 2019.

US GBC. Liderança em Construção Ecológica é LEED. Disponível em: https://www.usgbc.org. Acesso em: 14 nov. 2018.

VANZOLINI. Certificação AQUA em Detalhes. Disponível em: http://vanzolini.org.br/aqua/. Acesso em: 28 out. 2019.

VIDIGAL, I. P. N. A certificação ambiental como instrumento para a competitividade econômica e o desenvolvimento sustentável. In: XXI Encontro Nacional do Conselho de Pesquisa e Pós-graduação em Direito CONPEDI, Universidade Federal de Uberlândia - MG, 2012. 